\title{
Avaliação da escrita escolar: a importância e o papel dos critérios*
}

\section{The importance and role of criteria in the evaluation of writing}

\author{
Lívia Suassuna**
}

\begin{abstract}
RESUMO
No presente texto, discutimos a avaliação da aprendizagem da escrita no contexto escolar, enfocando, especificamente, a questão dos critérios. A partir dos dados de uma pesquisa anterior sobre como os professores encaminham o processo de devolução dos textos aos alunos após a correção, fizemos uma análise crítica dos procedimentos avaliativos empregados por uma docente dos anos finais do ensino fundamental de uma escola pública do município de Olinda (PE). Os dados foram coletados mediante observação de aulas de língua portuguesa, com audiogravação e registros em diários de campo, e sua análise foi baseada num referencial teórico centrado no conceito de avaliação formativa. Em seguida à discussão do corpus, mostramos uma possibilidade de trabalho que articule os processos de ensino, avaliação e aprendizagem. $\mathrm{O}$ estudo nos levou a reafirmar a importância e o papel dos critérios, qualquer que seja a dimensão do ato de avaliar a aprendizagem que esteja sendo considerada.
\end{abstract}

Palavras-chave: Avaliação da aprendizagem. Avaliação da escrita escolar. Critérios de avaliação. Produção de texto.

DOI: $10.1590 / 0104-4060.50676$

* A pesquisa se intitula Discursos sobre avaliação - o que se diz dos textos dos alunos e foi desenvolvida no âmbito do Programa Institucional de Bolsas de Iniciação Científica da Universidade Federal de Pernambuco. Dela participaram três bolsistas na época: Karla Renata de Lima, Maria Clara Sobral Galindo e Michelle Batista Bezerra, sendo as duas primeiras do curso de licenciatura em Letras e a última, do curso de Pedagogia.

** Universidade Federal de Pernambuco. Recife, Pernambuco, Brasil. Rua Acadêmico Hélio Ramos, s/n. Cidade Universitária. CEP: 50740-530. E-mail: liviasuassuna60@gmail.com 


\begin{abstract}
In the present text, we discuss the evaluation of the writing learning process in the school context, focusing, specifically, on the question of the criteria. Based on data from previous research on how teachers deal with the process of returning texts to students after correction, we have performed a critical analysis of the evaluation procedures employed by a teacher in the final series of elementary education at a public school in the municipality of Olinda (PE). The data were collected through observation of Portuguese language classes, with audio and field diary recording, and the analysis was based on a theoretical frame of reference centered on the concept of formative evaluation. Following the discussion of the corpus, we show a possibility of working approach that articulates the processes of teaching, evaluation and learning. The study led us to reassert the importance and role of criteria, regardless of the extent of the act of evaluating the learning in question.
\end{abstract}

Keywords: Learning Evaluation. Evaluation of School Writing. Evaluation Criteria. Text Output.

Um objeto absolutamente indiferente, totalmente óbvio, não poderia se tornar alguma coisa realmente reconhecida, efetivamente experimentada: quando tenho experiência direta de um objeto, quer dizer, quando de fato estou fazendo alguma coisa em relação a ele, esse objeto entra novamente em relação com alguma coisa que me coloco como tarefa, e que adquire densidade na minha relação com ele.

Mikhail Bakhtin

\title{
Introdução
}

Neste texto, discutiremos a avaliação da aprendizagem da escrita no contexto escolar, enfocando, especificamente, a questão dos critérios. Nosso interesse por essa temática se aprofundou quando realizamos uma pesquisa anterior sobre como os professores encaminham o processo de devolução dos textos aos alunos após a correção. A intenção foi, naquele momento, investigar quais eram as atividades desenvolvidas na devolutiva para que os alunos revisassem e reescrevessem suas produções e, em decorrência desse processo, sistematizassem e aprendessem determinados conteúdos e procedimentos de escrita. Ao longo da investigação, percebemos que a prática de uma das professoras observadas era marcada pela ausência de critérios de avaliação do texto; 
estes não eram traçados/explicitados nem antes de os alunos escreverem nem no momento da devolução dos textos. No caso específico dessa professora, isso resultava numa inconsistência do processo avaliativo, visto que as intervenções e os comentários eram pontuais, flutuantes e muito heterogêneos, dificultando o entendimento, pelos alunos, do que era problemático em seus textos, com vistas a melhorá-los. Faremos, então, uma análise crítica dos procedimentos de avaliação empregados por essa docente. Antes, vamos expor alguns pressupostos teóricos que embasaram nossa discussão. Em seguida à análise dos dados, mostraremos uma possibilidade de trabalho que articule os processos de ensino, avaliação e aprendizagem, salientando, para isso, a importância e o papel dos critérios. Por último, virão as considerações finais do estudo.

\section{Pressupostos teóricos}

De acordo com Gatti (2003), a avaliação da aprendizagem é uma das formas de acompanhamento das atividades dos alunos, com o objetivo de promover sua progressão. Ela oferece informações relevantes para o desenvolvimento do ensino na sala de aula e permite acompanhar e compreender como os processos de aprendizagem escolar estão se concretizando. É inegável, portanto, a importância da avaliação para fins de orientação, planejamento, execução e replanejamento do ensino.

Apesar disso, a autora chama a atenção para um fato que merece reflexão: um alto percentual dos alunos não consegue explicitar os critérios das notas e conceitos que os professores lhes atribuem. Frente a esse dado, deve-se levar em conta duas necessidades: (a) a de que o professor tenha claras suas concepções acerca da avaliação e do seu papel no trabalho desenvolvido com os aprendizes; (b) a de que o professor aprimore os meios e as formas de avaliação, de modo a

[...] criar e ajustar procedimentos avaliativos que sejam os mais adequados aos seus objetivos de ensino, à linguagem dos conteúdos tratados e à linguagem de seus alunos, e que possam contribuir não só para situar o grupo de alunos e cada aluno face à sua aprendizagem, mas também para estimular essa aprendizagem. (GATTI, 2003, p. 102).

Discutindo especificamente a questão da atribuição de pontos, notas e conceitos, a autora defende que esta seja consistente e equivalente de aluno 
para aluno. Ademais, um padrão de correção deve ser estabelecido cuidadosamente antes da aplicação do instrumento e discutido posteriormente com os alunos. Deve-se ter clareza com relação aos aspectos mais importantes a serem avaliados, não apenas em termos do tópico específico que está sendo tratado, mas em termos de seu significado "na formação da criança ou jovem, formação esta mais amplamente compreendida" (GATTI, 2003, p. 110). Logo, não basta apenas medir ou levantar dados por meio de testes, provas, questionários ou outras atividades; esses instrumentos, diz Gatti, dão base para se começar um processo avaliativo, mas não são suficientes. É preciso ir mais além e inferir, comparar, analisar consequências, examinar o contexto, estabelecer valores, aquilatar atitudes e formas de comunicação, entre outras ações.

Em estudo sobre o papel da avaliação no trabalho com a escrita escolar, Guerra (2006) alude às vantagens de implementar formas de avaliação processual para o desenvolvimento de competências necessárias à aprendizagem da escrita. Segundo esse autor, a avaliação é um pilar da aprendizagem, já que a produção do aluno é fortemente regrada pelos critérios de avaliação definidos pelo professor.

Guerra critica as formas tradicionais de avaliação, por serem normativas, parciais, estandardizadas e somativas. Em lugar desse modelo, propõe uma prática avaliativa de colaboração mútua, em que o aluno recupera a autoria e a autoridade de correção/adequação do seu próprio texto. Há quatro grandes vantagens no modelo proposto: (a) enfatizam-se o processo, o trabalho do escrevente e o binômio conteúdo/forma; (b) o professor assume uma atitude colaborativa na construção do texto; (c) flexibiliza-se a norma de correção; (d) a correção funciona como uma revisão do texto, visando ao seu melhoramento, e integra o processo de escrita como um todo.

O autor também afirma ser importante elaborar instrumentos e procedimentos de correção/avaliação diversificados e adaptados a produções textuais particulares. Destaca que o aluno não assimila muitas correções ao mesmo tempo, e, por isso, o professor deve se assegurar da pertinência da correção a ser operacionalizada em cada momento.

No que respeita aos critérios, Guerra afirma que o processo de avaliação se configura desde o início da produção. Assim, inicialmente, define-se um conjunto de critérios de avaliação que refletem aquilo que é pretendido na tarefa e que deve ser explicitado no seu enunciado. Depois se pode construir uma tabela classificativa que explicite os níveis e a caracterização de cada um deles, com base no que se espera da tarefa proposta. O próximo passo é escolher uma forma de dar retorno aos alunos, o que exige a elaboração de uma matriz de correção, a ser usada tanto no processo de construção textual quanto na apreciação das escritas. A partir daí o professor define a melhor sistemática para registrar e rever os progressos dos alunos. 
O autor destaca que a revisão/reescrita deve favorecer a compreensão, pelo discente, do seu processo de escrita. Nessa perspectiva, o erro tem uma dimensão positiva, exatamente por proporcionar a chance de rever as escolhas e seus efeitos de sentido. Com efeito, busca-se que o aluno desenvolva capacidades críticas diante de seus conhecimentos sobre a escrita. Por tudo isso se pode dizer que os critérios são a base de uma avaliação formativa autêntica. Eles teriam uma dupla finalidade: de um lado, auxiliam o professor a selecionar aspectos e fenômenos pertinentes para o encaminhamento da análise textual, a planejar a mediação didática a ser feita e a definir/hierarquizar os problemas a serem tratados (que, como já se comentou acima, não podem ser abordados todos de uma vez); de outro lado, auxiliam o aluno na análise e na regulação da tarefa de escrita, bem como na verificação da própria atuação no projeto discursivo que pretendeu realizar.

Finalmente, Guerra fala da importância de o professor ensinar os próprios alunos a elaborar/propor critérios de avaliação de textos, para o que seriam relevantes ações como comparar escritos a partir de tarefas, analisar textos diversos (inclusive não escolares), retextualizar produções, entre outras. Defende, ainda, que os critérios de avaliação devem ser flexíveis e que a especificação dos problemas detectados precisa estar formulada numa linguagem clara e acessível.

Outro estudo que trazemos aqui é o de Fairchild (2007). Para esse autor, não é possível trabalhar simultaneamente com todos os aspectos textuais e discursivos envolvidos na produção do texto a cada vez. Sendo assim, "pelo menos em alguns momentos é necessário que o trabalho se paute no ensino de aspectos específicos de leitura e escrita, ao custo de deixar de lado, momentaneamente, outras questões que também poderiam ser tematizadas em aula" (FAIRCHILD, 2007, p. 232).

O autor sustenta que é necessário construir no aluno uma postura analítica em relação ao seu trato com a língua. Para tanto, seria preciso criar, progressivamente, um repertório de recursos e estratégias que podem ser mobilizados, de modo mais ou menos consciente, quando ele tiver de lidar com seus "impasses linguageiros" (FAIRCHILD, 2007, p. 232). Daí que o trabalho de avaliação envolve, também, conhecer a maneira como o aluno lida com a língua.

Fairchild (2007) propõe, então, que o processo avaliativo se dê em dois tempos: avaliação prognóstica e avaliação diagnóstica. A primeira consistiria em fazer descrições da leitura e da escrita do aluno e, a partir disso, identificar os elementos que podem orientar a elaboração de atividades de linguagem para serem realizadas na sequência; já a segunda, correlatamente, consiste em montar estratégias para intervir e averiguar os efeitos das atividades desenvolvidas sobre aspectos específicos da leitura e da escrita do aluno. 
Morais e Ferreira (2007) reconhecem que a avaliação da produção do texto escrito depende muito da postura do professor diante das atividades propostas para essa finalidade, assim como diante das escritas dos alunos. No entanto, defendem que há um elemento da avaliação formativa que também deve ser valorizado e estimulado: a autoavaliação, prática fundamental para que os aprendizes se tornem escritores autônomos. Dizem os autores:

\begin{abstract}
Nesse processo é importante explicitar para os alunos os critérios de avaliação que o professor utiliza para que o aluno, na releitura compartilhada ou individual do seu texto e por meio da leitura dos textos dos colegas, possa identificar as "faltas" e reconstruí-las. Assim, além de favorecer aos alunos um momento de reflexão, essa atividade avaliativa está dando-lhes condições de construir um sistema pessoal para aprender a escrever, que poderá ser enriquecido progressivamente. (MORAIS; FERREIRA, 2007, p. 79).
\end{abstract}

A última autora que citamos é Brandão (2007), que salienta a relevância do trabalho de revisão textual na sala de aula. Segundo ela, a revisão constitui-se como um objeto de ensino e, nessa condição, merece um planejamento da parte do professor, de modo a gerar situações significativas de interação através da escrita nas quais se possa rever e reelaborar o texto. A revisão, enquanto parte do processo de produção textual, exige que o autor reflita sobre o que efetivamente escreveu, avaliando o texto com base no planejamento, nos objetivos traçados, no destinatário previsto, no contexto geral da interação. Isso faz da revisão uma atividade metacognitiva complexa, a qual requer um pensar consciente sobre $o$ ato de escrever, os processos de construção textual e as decisões tomadas.

Nesse contexto, é papel do professor promover e compartilhar a revisão dos textos dos alunos, vista como um elemento-chave para a formação de produtores autônomos e competentes, aqueles que, nas diversas situações de interação mediadas pela escrita, podem elaborar textos e refletir sobre as diferentes possibilidades da língua escrita, analisando seus efeitos sobre o interlocutor, tomando decisões sobre o que dizer e como dizer.

Diante dos pressupostos citados, é evidente a relevância dos critérios dentro de um processo de avaliação em geral e da produção textual em particular. Eles funcionam como um referencial de construção e reconstrução do texto e contribuem, certamente, para a efetivação da aprendizagem dos discentes. 


\section{Metodologia}

Os dados do conjunto da pesquisa foram coletados a partir da observação da prática de cinco professoras de português dos anos finais do ensino fundamental de três redes municipais de ensino da região metropolitana de Recife (PE), escolhidas por terem integrado, em momento anterior, um projeto intermunicipal de avaliação de rede escolar. Para o registro dos dados, utilizamos gravador de voz tipo MP3 e anotações em diário de campo. Todas as docentes observadas, assim como os gestores de suas escolas, assinaram um Termo de Consentimento Livre e Esclarecido para participação em pesquisa, no qual estavam assegurados o anonimato de escolas, professoras e alunos, e o direito de desistir da pesquisa a qualquer tempo por parte de qualquer um dos sujeitos.

Como havia três bolsistas, conforme já dito, cada uma ficou responsável por um subprojeto específico, dentro do objetivo maior que era analisar como os textos dos alunos, depois de avaliados pelas professoras, retornavam para a sala de aula. Assim, a primeira graduanda verificou como a docente, tendo identificado as dificuldades dos alunos, encaminhava sequências ou ações didáticas apropriadas para saná-las; a segunda verificou se a ação da escrita se articulava com as de leitura e análise linguística; já a terceira verificou que critérios de avaliação guiavam a professora e a turma, e se esses critérios eram adequadamente explicitados. Este estudo, em particular, corresponde a um recorte do terceiro subprojeto. Acompanhamos o trabalho desenvolvido numa turma de $6^{\circ}$ ano. Tratava-se de uma escola de periferia e a turma, composta de 27 alunos entre 11 e 13 anos, funcionava no turno matutino.

A proposta de escrita da qual resultaram os textos que analisamos foi lançada pela professora alguns dias antes do Dia Internacional da Mulher, dentro do costume de se solicitar redações sobre temáticas relacionadas ao calendário cívico. Para inserir os alunos na temática definida e motivá-los a escrever, a professora trouxe para a sala de aula uma reportagem de um jornal local de grande circulação, intitulada "A mulher é quem tem que dar o basta". A matéria jornalística era comemorativa de mais um ano da instituição da Lei Maria da Penha (BRASIL, 2006), que foi criada para coibir a violência doméstica e familiar contra a mulher. O texto trazia informações diversas, fotos e depoimentos de vítimas da violência, de gestores públicos e estudiosos do assunto (psicólogos, advogados e sociólogos). A ênfase recaía na necessidade de que as vítimas denunciassem os seus agressores para que houvesse maior efetividade da lei.

Após a leitura coletiva da reportagem, a professora solicitou que os alunos, individualmente, produzissem um texto sobre o tema. Ela não especificou 
nenhum gênero textual, destinatário ou finalidade, apenas exigiu que o título fosse o mesmo da reportagem. Notamos, no momento da encomenda do texto, que os alunos ficaram um pouco angustiados por não saber exatamente o que deveria ser feito. Vimos, por exemplo, diálogos como:

A-Professora, é pra fazer um texto como?

$P$ - Um texto, como esses que vocês estão acostumados a fazer.

A-Professora, eu faço um texto sobre o mesmo tema do jornal ou dizendo o que eu achei?

$P$ - Tanto faz.

Na sequência, os alunos começaram a escrever em folhas de caderno grande e entregaram as produções à professora ao final da aula. Os textos foram levados pela professora, corrigidos em casa e, na aula seguinte, devolvidos aos alunos. Não foram desenvolvidas atividades de revisão/reescrita, nem foram tecidos comentários gerais ou individualizados sobre os desempenhos dos alunos. Na avaliação, a professora procedeu de formas variadas, mas verificamos que em todas as amostras foram feitas correções no próprio texto do aluno (a maioria de ordem gramatical) e indicou-se o conceito conforme o sistema vigente na rede de ensino: DC, DEC ou DNC, significando, respectivamente, desempenho construído (= bom), desempenho em construção (= regular) e desempenho não construído (=insuficiente). A tarefa foi cumprida pelos 24 alunos presentes nesse dia e tivemos acesso a todos os textos depois de corrigidos pela professora, que foram fotocopiados antes da devolução. A nenhuma das produções foi atribuído o conceito DC.

\section{Análise e discussão dos dados}

Analisamos os 24 textos produzidos, ora global, ora pontualmente. Na maioria (14) havia desenhos feitos pelos alunos, todos correlacionados ao que havia sido escrito. No geral, os alunos procuraram fazer narrativas de episódios de violência contra a mulher. Os textos eram curtos e os conceitos a eles atribuídos foram DNC (16 ocorrências) e DEC (8 ocorrências). Na ausência de 
critérios claros e consistentes de construção e avaliação dos textos dos alunos, constatamos alguns pontos problemáticos, que passamos a expor.

1. Falta consistência entre o comentário da professora e o conceito atribuído à produção: o aluno escreveu um texto dizendo o que havia entendido/ lembrado da reportagem (Figura 1); a docente fez várias correções gramaticais, atribuiu conceito DEC e, nos comentários, registrou: Embora você não tenha escrito bastante, percebi que prestou atenção na leitura. Continue assim. Supõe-se aqui que ela esperava um tamanho mínimo para o texto e a reprodução de algumas informações presentes na reportagem. Mas o que queremos destacar é que ao aluno foi recomendado que continuasse com aquele padrão de escrita que a própria professora havia considerado regular, por meio do conceito DEC. ${ }^{1}$

\section{FIGURA 1 - TEXTO 1}
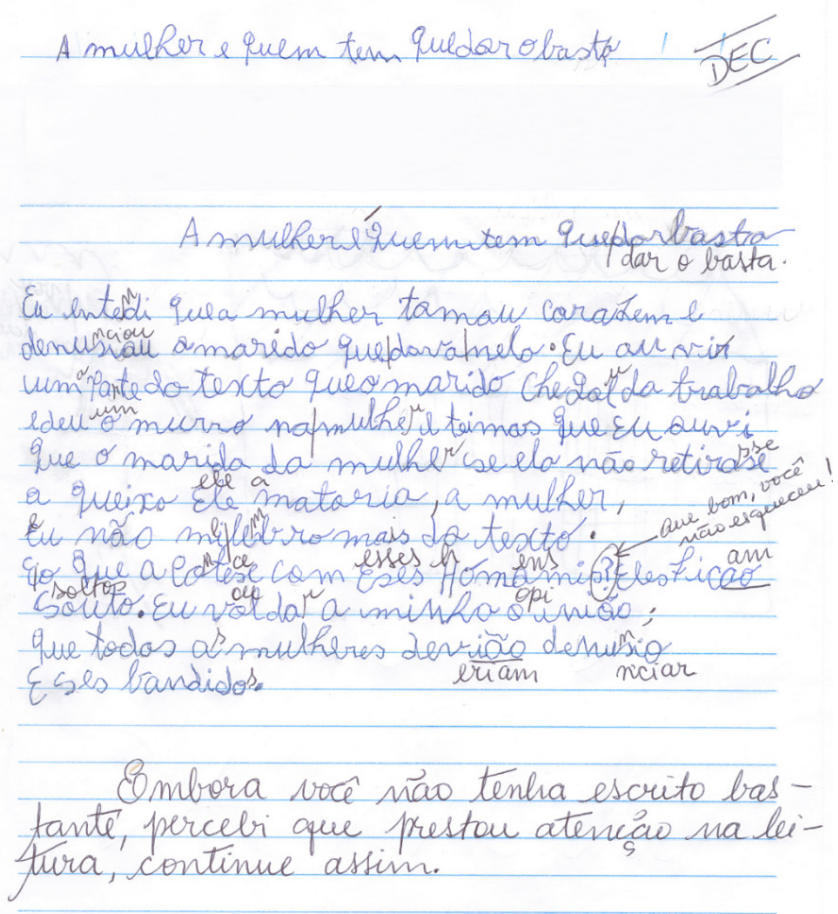

FONTE: Arquivo pessoal da autora.

1 A partir de agora, inseriremos alguns textos de alunos para ilustrar/demonstrar nossas ideias. Todos os exemplares mostrados pertencem à amostra detalhada no item Metodologia. Preservamos a numeração dos textos traçada na pesquisa original. 
2. Alguns alunos supervalorizaram, talvez em função de sua vivência, cenas de violência, seja recontando o que estava narrado na reportagem, seja criando fatos, seja aludindo a situações efetivamente presenciadas por eles (Figura 2). O fato é que, quando as narrativas pareceram excessivamente trágicas, a professora teceu comentários apenas sobre isso. Assim, encontramos os seguintes registros: (a) Você não prestou atenção na leitura do texto, por isso escreveu coisas que não têm a ver com o que foi comentado; (b) Você tem imaginação fértil; não conversamos sobre isso na sala de aula; (c) Você não prestou atenção na leitura.

FIGURA 2 - TEXTO 3

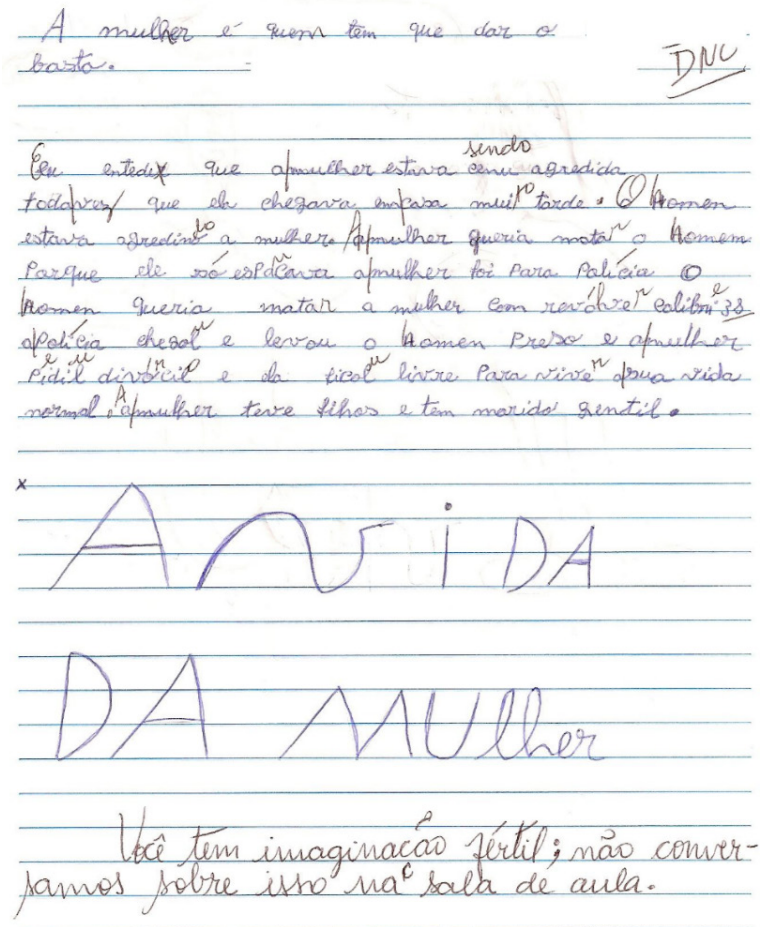

FONTE: Arquivo pessoal da autora.

3. Houve uma preocupação da professora com a extensão dos textos, só revelada quando da correção (Figura 3). São exemplos desse critério os textos em que apareceram os seguintes comentários: (a) Você deveria ter escrito um pouco mais; (b) Você podia ter escrito mais sobre o assunto (duas ocorrências); (c) Você deveria ter escrito mais, percebi que prestou atenção na leitura; (d) 
Por que não escreveu mais sobre o tema? Não deu para avaliar como gostaria; (e) Você prestou atenção no texto que leu, mas escreveu pouco sobre o assunto. Vale salientar que, no caso (c), produção não se configurava como uma retomada da reportagem, pois o aluno desenvolveu muito mais opiniões pessoais do que as ideias contidas no texto gerador.

FIGURA 3 - TEXTO 12
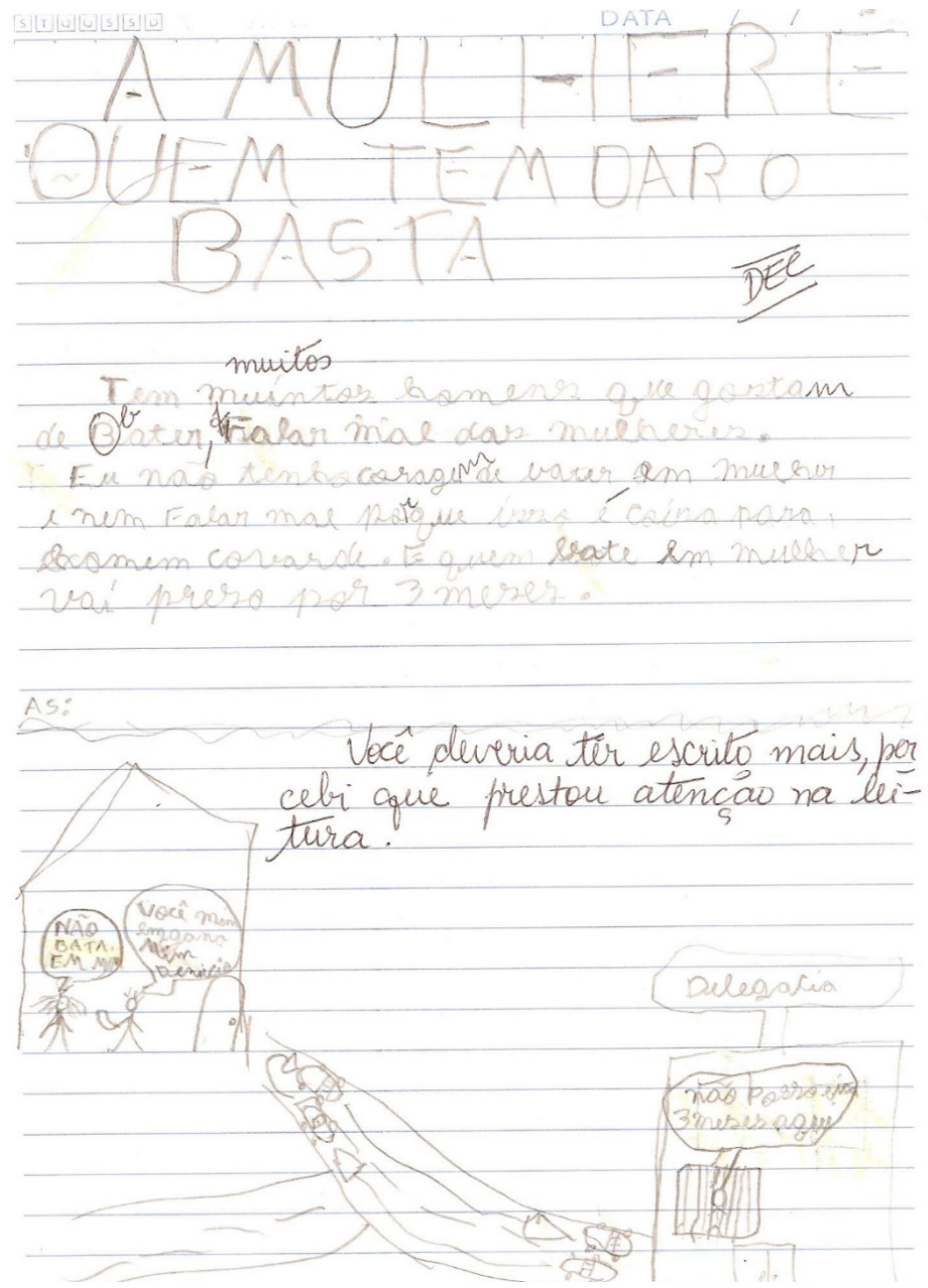

FONTE: Arquivo pessoal da autora. 
4. Em termos da correção gramatical, grande parte se deu em relação a regras ortográficas e de concordância verbal e nominal (Figura 4). Algumas falhas eram deixadas de lado, não sabemos se porque a professora não valorizou ou porque não percebeu. O fato é que todos os textos ainda continham erros, mesmo após a revisão da docente. Constatamos também a supervalorização de aspectos pontuais; por exemplo: diante de um ponto de interrogação corretamente empregado, a professora registrou:-Que bom, você não esqueceu!. Esse, aliás, foi o único comentário explícito sobre o emprego de sinal de pontuação.

FIGURA 4 - TEXTO 20

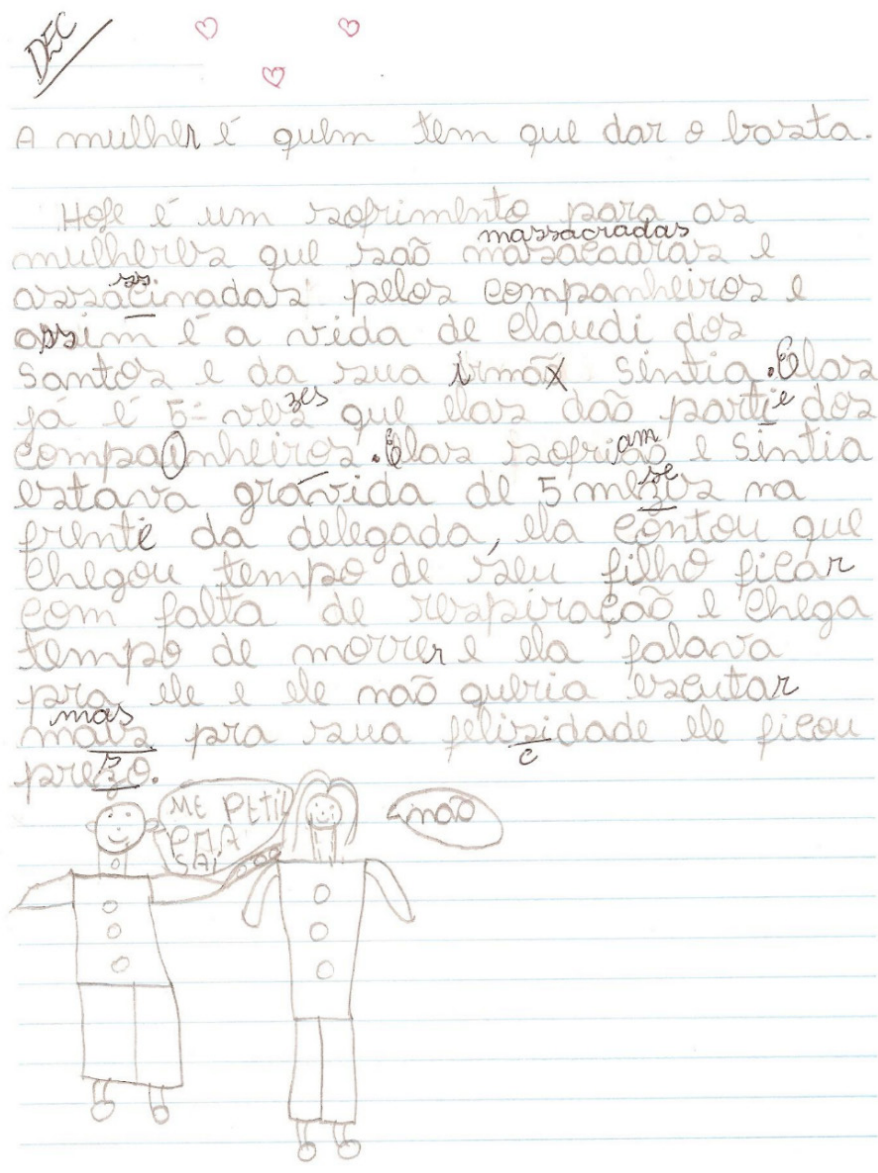

FONTE: Arquivo pessoal da autora. 
5. Alguns comentários eram excessivamente vagos e, desse modo, não poderiam funcionar como instrução ou orientação para que os alunos melhorassem os textos (Figura 5). São exemplos disso os registros a seguir: (a) Verifique seus erros e procure não repeti-los; (b) Você precisa exercitar a escrita; (c) Preste atenção para não repetir as palavras; (d) Procure organizar seu pensamento e não repetir tanto as palavras; (e) Podia ter organizado melhor as ideias; (f) Tente formular as frases de modo que se possa compreender o que você escreveu.
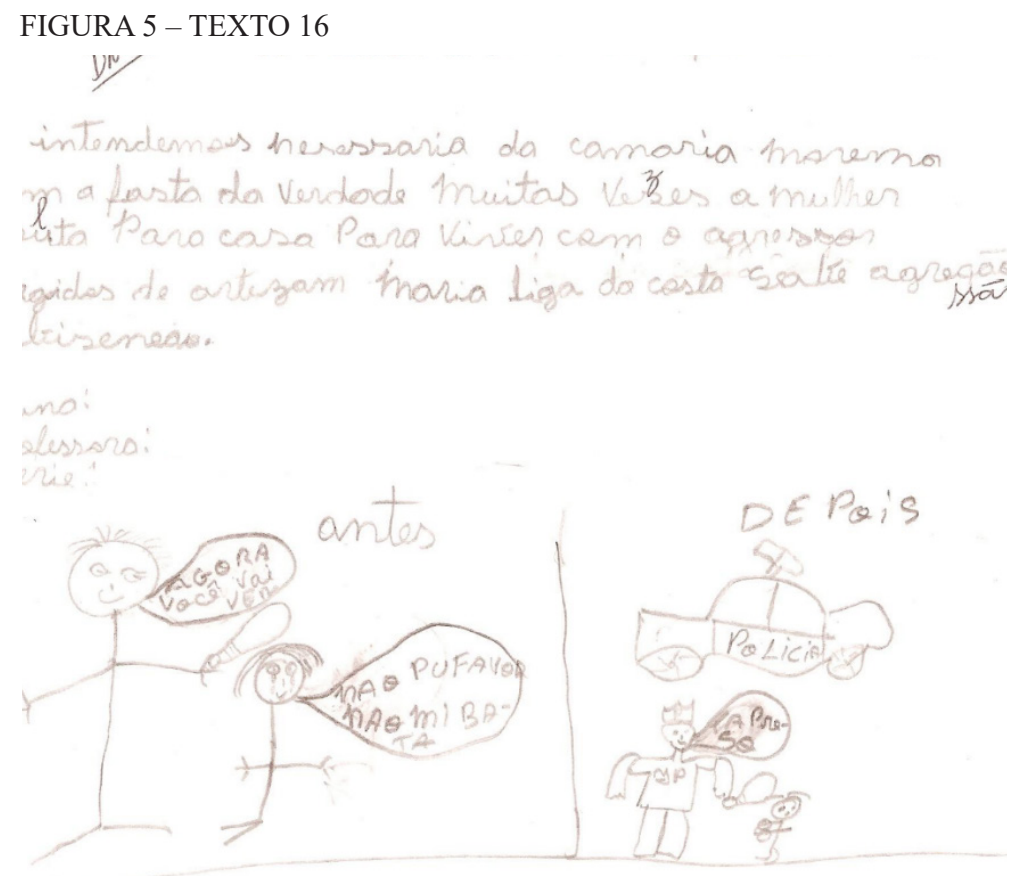

\section{Vocè precisa exercitar a escrita.}

FONTE: Arquivo pessoal da autora.

6. Os conceitos adotados, embora fossem parte do sistema de avaliação de toda a rede de ensino em questão, não podiam ser relacionados a um espectro de indicadores de desempenho. Dessa forma, textos muito diferentes entre si, com níveis muito distintos de correção e adequação, acabaram por receber uma mesma menção (DEC, no caso), sem que se soubesse que propriedades mínimas 
deveriam ter sido garantidas a um texto para que ele fosse considerado regular; o mesmo aconteceu para os textos que receberam DNC. Também constatamos que textos igualmente problemáticos foram avaliados com conceitos distintos. Comparem-se os dois textos, aos quais se atribuíram as menções DEC e DNC (Figuras 6 e 7).

FIGURA 6 - TEXTO 24

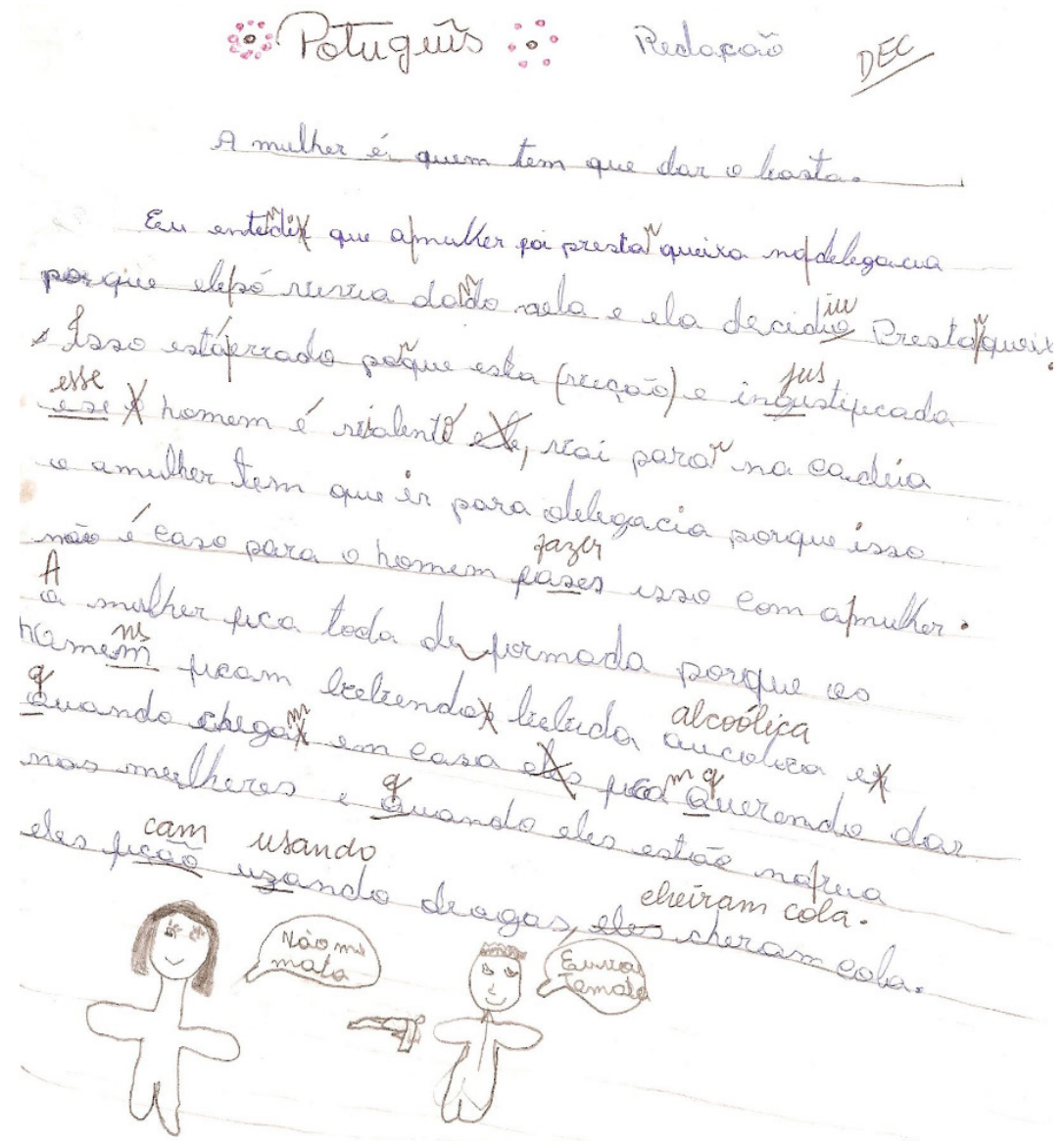

FONTE: Arquivo pessoal da autora. 
FIGURA 7 - TEXTO 11

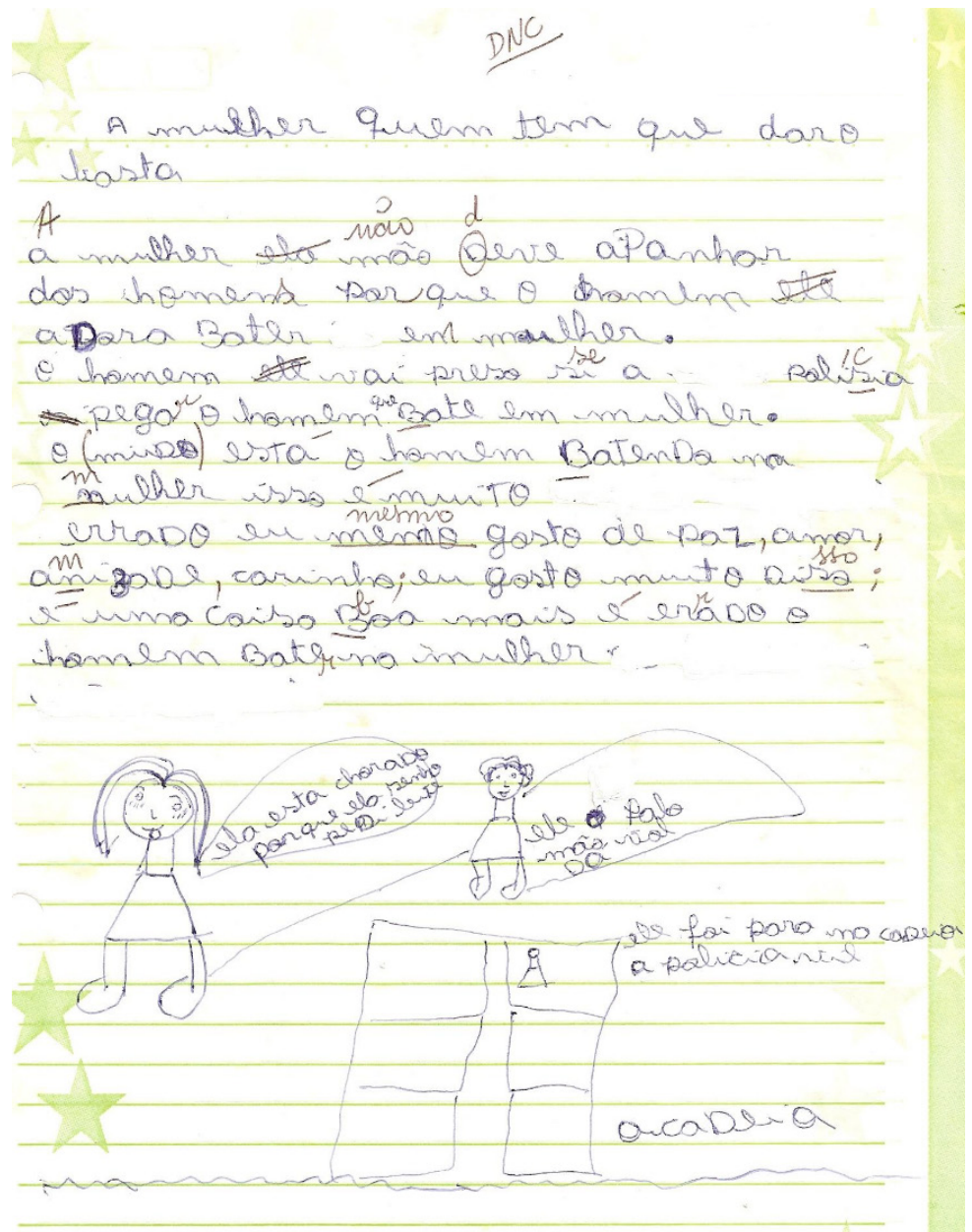

FONTE: Arquivo pessoal da autora.

7. Não nos pareceu que os comentários da professora contivessem elementos e conceitos metalinguísticos conhecidos dos alunos para que eles pudessem, por eles mesmos, analisar e reconstruir os trechos apontados como errados ou problemáticos em termos estruturais. Por exemplo: em duas produções, os discentes, ao lado dos desenhos que haviam produzido, colocaram balões semelhantes aos utilizados em gibis, mas, em vez de escreverem falas em primeira 
pessoa, como seria esperado, inseriram falas de narradores em terceira pessoa (Figura 8). A professora, então, empregou os conceitos de pessoa gramatical, narrador e personagem para apontar a falha dos alunos e, como os textos não foram discutidos nem revisados, temos dúvida de que tenha ocorrido uma modificação adequada da estrutura a partir da compreensão do fato pelos alunos.

Aproveitaremos esse último caso para discutir uma forma de avaliação que consideramos adequada para tratar de uma dificuldade específica relacionada à escrita do aluno. Faremos nossas considerações a partir de um exemplo de nossa amostra, embora tenhamos achado a temática desinteressante para os alunos. Além disso, na ocasião não se constituiu um contexto discursivo apropriado no qual eles pudessem e quisessem se posicionar por meio de suas falas tendo em vista algum interlocutor. Também não se definiu um gênero textual a ser elaborado, tampouco uma finalidade para o dizer. Vale destacar que esses elementos - tema, destinatário, gênero textual, finalidade -, entre outros, se configurariam como parte dos critérios de construção e apreciação das produções.

De todo modo, vejamos a ocorrência que nos interessa comentar neste ponto. Um dos alunos escreveu o seu texto, assim como os colegas, usando um lado de uma folha de caderno. No verso, ele fez um desenho, reproduzido abaixo.

FIGURA 8 - VERSO DO TEXTO 8



FONTE: Arquivo pessoal da autora. 
No recorte acima, veem-se um homem à esquerda, com um bastão na mão, e uma mulher à direita. Acima dos dois, está uma explicação, como se fosse uma fala de um narrador: Ele está dando uma paulada na cabeça da mulher. No balão correspondente à figura do homem está escrito: ele disse se não tira a quecha vai da uma paulada; no balão correspondente à mulher, temos: e ela disse que nao i a tira a quecha. A professora registrou um comentário, tendo antes ligado os dois balões, como a sugerir que o problema destacado estava em ambos. Diz ela: Não é fala dos personagens e sim do narrador.

Esse contexto contém, como percebido pela professora, um conteúdo relevante a estudar: diferenças entre narrativas em quadrinhos e narrativas em prosa; dentro disso se poderia trabalhar com tipos de narrador, discurso direto e indireto e pessoa gramatical. Como vários autores sugerem, não se poderia trabalhar ao mesmo tempo com muitos aspectos de todos os textos produzidos pela turma. Então, conforme uma programação curricular prévia, os objetivos de ensino e as metas de aprendizagem traçados para o grupo-classe, o nível de conhecimento dos discentes, o professor (re)define certos objetos de ensino-aprendizagem a partir de sua ocorrência em alguns escritos dos alunos. E justamente na devolutiva é que as construções seriam problematizadas, comparadas, explicadas, refeitas... em função de certos efeitos de sentido que se queira produzir.

Portanto, para que os alunos compreendam o problema de construção da narrativa em questão, particularmente a inserção das falas dos personagens no texto, cremos que não seria suficiente apenas dizer "Não é fala dos personagens e sim do narrador". Antes, seria necessário que eles tivessem contato com novas narrativas em prosa e em quadrinhos, e fossem levados a identificar falas numas e noutras para tirar alguma conclusão sobre os procedimentos utilizados pelos autores para manejar as falas que se quer inserir no texto.

Esse processo de identificação, reflexão, comparação e dedução de regras, demandando a mobilização de determinados conceitos e de uma determinada nomenclatura, levaria à construção do conhecimento. E assim a avaliação cumpre seu principal propósito, que é acompanhar e assegurar a aprendizagem. Nessa perspectiva, os critérios são imprescindíveis, porque podem, de um lado, orientar as estratégias a serem empregadas pelo professor para ensinar e avaliar, e, de outro, traduzir o que se espera dos aprendizes, orientando-os no processo de escrita (que envolve planejamento, escrita, revisão e reescrita). 


\section{Considerações finais}

Numa entrevista concedida à revista Presença Pedagógica, Dale Armstrong (2004) revela sua visão da avaliação como importante instrumento para a melhoria do processo ensino-aprendizagem. Discorrendo sobre os modelos formativo e somativo, o estudioso afirma que ambos são essenciais, mas que a avaliação formativa é, principalmente, uma avaliação para o aprendizado e deve acontecer continuamente em sala de aula, no trabalho direto com os estudantes. Esse tipo de avaliação requer que o docente dê retorno ao aluno sobre aspectos específicos do seu desempenho.

No que respeita à nota, Armstrong reconhece que esse é um tema delicado e considera que não existe um sistema muito melhor do que outro. A questão, para ele, é que os pontos não deveriam ter tanta importância, justamente porque o mais importante é o retorno que se pode dar ao aluno e não sua nota final. Disso decorre a necessidade de trabalhar com rubricas, pois elas, quando explicitadas e detalhadas, aumentam as chances de realização de uma avaliação consistente.

Outro imperativo da avaliação formativa é que exista "um alinhamento entre o que devemos ensinar (o currículo), o que ensinamos efetivamente e o que cobramos na avaliação" (ARMSTRONG, 2004, p. 8). Nessa perspectiva, garante-se o significado da nota, visto que ela reflete o desempenho do aluno, comparado com aquilo que, no currículo, foi definido como relevante para ele em seu estágio de desenvolvimento e conforme seus interesses e potencialidades.

Ao longo da entrevista, Armstrong deu exemplos de suas teses acerca da avaliação em várias áreas do conhecimento escolar. No caso da língua e da escrita, ele argumenta que o melhor meio de transformar estudantes em bons escritores é deixar que eles escrevam e provê-los com um retorno específico a respeito dos textos produzidos.

Em síntese, a avaliação é, indiscutivelmente, um campo multirreferencial e, qualquer que seja a dimensão dela que esteja em jogo - o ensino, a aprendizagem, o desempenho, o sistema de notas, a ética, o currículo etc. -, os critérios sempre vão ter que estar presentes. 


\section{REFERÊNCIAS}

ARMSTRONG, D. Uma visão contemporânea da avaliação. Entrevista concedida a Rita Espechit. Presença Pedagógica, Belo Horizonte, MG, v. 10, n. 57, p. 5-17, maio/jun. 2004.

BAKHTIN, M. Para uma filosofia do ato responsável. São Carlos: Pedro \& João Editores, 2010.

BRANDÃO, A. C. P. A revisão textual na sala de aula: reflexões e possibilidades de ensino. In: LEAL, T. F.; BRANDÃO, A. C. P. (Orgs.). Produção de textos na escola: reflexões e práticas no ensino fundamental. Belo Horizonte: Autêntica, 2007. p. 119-134.

BRASIL. Lei $n^{\circ}$ 11.340, de 7 de agosto de 2006. Lei Maria da Penha. Brasília, 2006.

FAIRCHILD. T. M. Avaliação em dois tempos no trabalho com o texto. Olhar de Professor, Ponta Grossa, PR, v. 10, n. 1, p. 231-251, 2007. Disponível em: $<$ http://www. uepg.br/olhardeprofessor>. Acesso em: 01 dez. 2016.

GATTI, B. A. O professor e a avaliação em sala de aula. Estudos em Avaliação Educacional, São Paulo, SP, n. 27, p. 97-114, jan./jun. 2003.

GUERRA, J. A avaliação do escrito. Desenredo, Passo Fundo, RS, v. 2, n. 2, p. 179-187, jul./dez. 2006.

MORAIS, A. G.; FERREIRA, A. T. B. Avaliação do texto escrito: uma questão de concepção de ensino e aprendizagem. In: LEAL, T. F.; BRANDÃO, A. C. P. (Orgs.). Produção de textos na escola: reflexões e práticas no ensino fundamental. Belo Horizonte: Autêntica, 2007. p. 65-80.

Texto recebido em 14 de fevereiro de 2017.

Texto aprovado em 14 de abril de 2017. 
